Article

\title{
Enhancing the Robustness and Efficiency in the Production of Medium Mn Steels by Al Addition
}

\author{
Maokun Bai ${ }^{1}$, Dapeng Yang ${ }^{1}$, Guodong Wang ${ }^{1}$, Joohyun Ryu ${ }^{2}$, Kyooyoung Lee ${ }^{2}$ \\ and Hongliang $\mathrm{Yi}^{1}{ }^{1} * \mathbb{D}$ \\ 1 State Key Laboratory of Rolling and Automation, Northeastern University, Shenyang 110819, China; \\ bmk219hh@163.com (M.B.); yangdapeng6@163.com (D.Y.); wanggd@mail.neu.edu.cn (G.W.) \\ 2 Technical Research Laboratories, Gwangyang-si 545-875, Korea; ryujh@posco.com (J.R.); \\ kylee1@posco.com (K.L.) \\ * Correspondence: hlyi@ral.neu.edu.cn; Tel.: +86-024-83686422
}

Received: 25 September 2020; Accepted: 26 October 2020; Published: 28 October 2020

\begin{abstract}
The narrow process window during intercritical annealing and discontinuous yielding have limited the commercialization of medium Mn steels. In this study, a double-annealing process based on the commercial continuous annealing line is proposed. The cold-rolled medium Mn steels were first fully austenitized and quenched during the first annealing, followed by intercritical annealing for reverted austenite transformation. The microstructure of duplex lath-shaped austenite and ferrite is produced and steel exhibits a desirable continuous yielding during tensile deformation. Al is added into the medium Mn steel to enlarge the process window and to improve the partitioning efficiency of $\mathrm{Mn}$. The produced steel is more robust with temperature fluctuation during the industrial process due to the enlarged intercritical region. Mn partitioning is more efficient owing to the elevated annealing temperature, which results in the improvement of ductility in the Al-added steel with increased austenite stability.
\end{abstract}

Keywords: medium Mn steel; Al addition; intercritical annealing; temperature sensitivity; Mn partitioning

\section{Introduction}

Medium Mn steels containing 5-10 wt\% Mn have been listed as one of the third-generation advanced high-strength steels for automobile application due to their attractive combination of strength and plasticity [1-9]. The superior mechanical properties are mainly originated from the transformation of metastable austenite into hard martensite during deformation, namely the transformation-induced plasticity (TRIP) effect [4,7,10-13]. In general, the volume fraction of $20 \%$ to $50 \%$ metastable austenite is retained in the final microstructure of medium Mn steels, which is greater than that of the conventional TRIP-assisted steels [2,4-6,9,14-17].

The excellent mechanical properties of medium Mn steels are highly dependent on the partitioning of $\mathrm{C}$ and $\mathrm{Mn}$ from martensite/ferrite to austenite. Furthermore, the distinct $\mathrm{C}$ and Mn partitioning can be realized in the severely deformed martensite after intercritical annealing for several minutes. The heat treatment process is suitable for continuous annealing lines in industry [18-20]. However, an ultrafine and globular austenite and ferrite microstructure will be formed after the above heat treatment process, leading to discontinuous yielding accompanied by Lüders strain during tensile deformation. This mechanical performance is not favorable to the formability of the steel sheet due to severe localized thinning and also results in a rough surface of the stamping parts [21-25].

Continuous yielding without Lüders strain will be produced when the microstructure consists of lath-shaped austenite and ferrite, evolving from the undeformed martensite during intercritical 
annealing [5,22,24]. A good combination of strength and plasticity can be achieved with this initial microstructure only when the annealing duration is higher than several hours to realize sufficient $\mathrm{Mn}$ partitioning which is only suitable for the batch annealing process in industry [26,27]. However, close control of the temperature variation is needed to produce a uniform microstructure and mechanical properties, making industrial production of this steel type difficult [4,22]. In addition, the increase in volume fraction of austenite during intercritical annealing is due to the growth of $\gamma$ nucleated at the martensite lath boundaries and this process is controlled by the diffusion of Mn [5]. Therefore, a long annealing duration is required to stabilize the austenite on account of the slow diffusion of $\mathrm{Mn}$.

When $\mathrm{Al}$ is added, the intercritical annealing temperature range can be expanded $[10,23]$. Hence, the temperature sensitivity issue during intercritical annealing in medium Mn steels could be improved. At the same time, the annealing temperature of the steels could also be increased to obtain a sufficient amount of austenite. As a result, the diffusion efficiency of $C$ and Mn will be elevated due to the high kinetics at the raised temperature and then the relatively short time may be enough to implement the partitioning of $\mathrm{C}$ and $\mathrm{Mn}$ into austenite. For the mentioned reasons, it is possible to produce a predominantly lath-shaped microstructure in medium $\mathrm{Mn}$ steels in commercial continuous annealing lines. Accurate control of the temperature at a range of $\pm 5^{\circ} \mathrm{C}$ in a continuous annealing line is also beneficial to achieve a uniform microstructure and mechanical properties.

In the present work, $2 \mathrm{wt} \% \mathrm{Al}$ is added into medium $\mathrm{Mn}$ steel with the nominal composition of Fe-8Mn-0.15C ( $w \mathrm{t} \%)$. The cold-rolled specimens were fully austenitized and intercritically annealed at various temperatures to obtain the lath-shaped microstructure to eliminate discontinuous yielding. The microstructure and mechanical properties of the produced medium Mn steels with and without $\mathrm{Al}$ addition were investigated in detail.

\section{Materials and Methods}

The actual chemical composition of the investigated medium Mn steels is shown in Table 1. The $0 \mathrm{Al}$ steel and $2 \mathrm{Al}$ steel are named for simplification. An approximately $50 \mathrm{~kg}$ ingot of the dimension $\varnothing 450 \mathrm{~mm} \times 120 \mathrm{~mm}$ was cast on a vacuum induction furnace (Tongchuang Technology, Jinzhou, China). The ingot was reheated to $1200{ }^{\circ} \mathrm{C}$ for forging into a slab with a cross-section dimension of $35 \mathrm{~mm} \times 90 \mathrm{~mm}$, followed by air cooling. The slab was homogenized at $1200{ }^{\circ} \mathrm{C}$ for $5 \mathrm{~h}$ and hot-rolled to $3 \mathrm{~mm}$ between 1200 and $900{ }^{\circ} \mathrm{C}$, followed by air cooling. Finally, the hot-rolled plate was surface-descaled and cold-rolled to $1.5 \mathrm{~mm}$.

Table 1. Chemical compositions of medium Mn steels used in the present study (wt $\%)$.

\begin{tabular}{ccccc}
\hline Steels & C & Mn & Al & Fe \\
\hline $0 \mathrm{Al}$ & 0.15 & 7.9 & - & Bal. \\
$2 \mathrm{Al}$ & 0.15 & 8.0 & 1.8 & Bal. \\
\hline
\end{tabular}

The prior austenite grain size which is mainly determined by the austenitzation temperature has a significant influence on the evolution of the microstructure and mechanical properties of intercritically annealed medium Mn steel [28]. Therefore, a similar prior austenite grain size of the two studied steels was obtained to eliminate its influence on the subsequent microstructure and mechanical properties. Based on the literature of medium Mn steels in which the composition is similar and the previous research on medium Mn steels [26], the cold-rolled specimens were austenitized at $980{ }^{\circ} \mathrm{C}$ for the $0 \mathrm{Al}$ steel and $950^{\circ} \mathrm{C}$ for $2 \mathrm{Al}$ steel, followed by air cooling. The duration at the austenitization temperature was $5 \mathrm{~min}$. The $0 \mathrm{Al}$ steel was intercritically annealed at $640,650,660$ and $670{ }^{\circ} \mathrm{C}$ for $5 \mathrm{~min}$, while the $2 \mathrm{Al}$ steel was annealed at $670,680,690$ and $700{ }^{\circ} \mathrm{C}$ for $5 \mathrm{~min}$, to obtain $40-50 \%$ volume fraction of austenite. The intercritical annealing temperature and durations were designed based on the capabilities of an industrial continuous annealing line which has a higher-precision temperature control than batch annealing lines. The selective etching of the prior austenite grain boundary was performed using the saturated picric acid solution (Kaisa Chemical, Tianjin, China) 
with wetting agents (Jahwa, Shanghai, China) [29,30]. The prior austenite grain size was observed by standard optical microscopy (OM, Olympus BX53M, Tokyo, Japan) and measured using the mean linear intercept method [29]. The microstructure of the annealed specimens was observed in field emission transmission electron microscopy (TEM, Tecnai G2 F20, FEI, Hillsboro, OR, USA) combined with energy-dispersive spectroscopy (EDS, EDAX, Mahwah, NJ, USA) with an operating voltage of $200 \mathrm{kV}$. The volume fraction of austenite was measured by Bruker D8 ADVANCE X-ray diffractometer (Bruker, Billerica, MA, USA) with a $0.5 \mathrm{~mm}$ spot size of $\mathrm{Co} \mathrm{K} \alpha$ radiation.

The TEM specimen was first ground to the thickness of about $50 \mu \mathrm{m}$ and then punched to make a $3 \mathrm{~mm}$ diameter disk. The disk was electro-polished in 92\% ethanol (Fuyu Chemical, Tianjin, China) and $8 \%$ perchloric acid solution (Tiangang Chemical, Shenyang, China) under a voltage of $20 \mathrm{~V}$ at a temperature of $-25^{\circ} \mathrm{C}$ using a twin-jet polisher (Struers Tenupol-5, Buehler, Lakbluff, IL, USA). The specimens for XRD measurement were electro-polished using the same solution as the TEM specimen preparation at room temperature and the voltage of $25 \mathrm{~V}$ with a current of about $1.1 \mathrm{~A}$ for $25 \mathrm{~s}$ was set for the polishing equipment.

The volume fraction of austenite was calculated using the following equation [31]:

$$
V_{\gamma}=1.4 I_{\gamma} /\left(I_{\alpha}+1.4 I_{\gamma}\right),
$$

where $V_{\gamma}$ is the volume fraction of the retained austenite, and $I_{\gamma}$ and $I_{\alpha}$ are the mean integral intensity of the (200), (220) and (311) austenite peaks and the (200) and (211) ferrite peaks, respectively.

The average $C$ content of the retained austenite was obtained using the following equation [32]:

$$
a_{\gamma}=3.578+0.33 w_{\mathrm{C}}+0.0095 w_{\mathrm{Mn}}+0.0056 w_{\mathrm{Al}}
$$

where $w_{\mathrm{C}}, w_{\mathrm{Mn}}$ and $w_{\mathrm{Al}}$ are the concentrations of $\mathrm{C}, \mathrm{Mn}$ and $\mathrm{Al}(\mathrm{wt} \%)$ in the retained austenite, respectively, and $a_{\gamma}$ is the measured lattice parameter $(\AA)$ of austenite from X-ray diffraction.

The dog bone-shaped tensile specimens were taken along the rolling direction of the cold-rolled sheet with $12.5 \mathrm{~mm}$ width and a gauge length of $50 \mathrm{~mm}$ following the ASTM standard. The tensile specimens were acid-pickled to remove the oxide layer after intercritical annealing. The tensile test was performed on a universal tensile machine (MTS Test Technology, Jinan, China) at room temperature with a strain rate of $6.7 \times 10^{-4} \mathrm{~s}^{-1}$.

\section{Results and Discussion}

The equilibrium-phase fraction of $0 \mathrm{Al}$ steel and $2 \mathrm{Al}$ steel was calculated by the Thermo-Calc software (Version 2019a, Thermo-Calc Software, Stockhom, Sweden) using the TCFE9 database and is shown in Figure 1. Compared with $0 \mathrm{Al}$ steel, the amplitude of the intercritical region of $2 \mathrm{Al}$ steel is expanded. Therefore, the sensitivity of the microstructure to the annealing temperature in the Al-added medium Mn steel can be reduced in theory. In addition, a relatively higher annealing temperature of $2 \mathrm{Al}$ steel is obtained compared to that of $0 \mathrm{Al}$ steel if the same volume fraction of austenite is to be achieved during intercritical annealing.

The cold-rolled $0 \mathrm{Al}$ steel and $2 \mathrm{Al}$ steel after austenitzation and quenching treatment are both lath martensite in microstructure, as shown in Figure 2a,b. The measured linear intercept of the prior austenite grain is $17.1 \pm 1.4 \mu \mathrm{m}$ for $0 \mathrm{Al}$ steel and $17.7 \pm 1.7 \mu \mathrm{m}$ for $2 \mathrm{Al}$ steel (see inserted images at the upper right corners of Figure 2a,b) and the similar prior austenite grain size of both steels was obtained as expected. After intercritical annealing, both steels displayed the dominant lath-shaped austenite and ferrite microstructure, as shown in Figure $2 \mathrm{c}, \mathrm{d}$. The volume fraction of austenite in $0 \mathrm{Al}$ steel and 2Al steel after annealing at different temperatures is shown in Figure 2e. Compared to $0 \mathrm{Al}$ steel, the volume fraction of austenite in $2 \mathrm{Al}$ steel becomes relatively uniform after annealing at different temperatures. The experimental results indicate that the sensitivity of the austenite content to the annealing temperature is reduced by the addition of $\mathrm{Al}$, which is consistent with the calculation 
results (Figure 1). In addition, the volume fraction of austenite in $0 \mathrm{Al}$ steel annealed at $670{ }^{\circ} \mathrm{C}$ and $2 \mathrm{Al}$ steel annealed at $700{ }^{\circ} \mathrm{C}$ decreases due to partial martensite transformation during cooling.

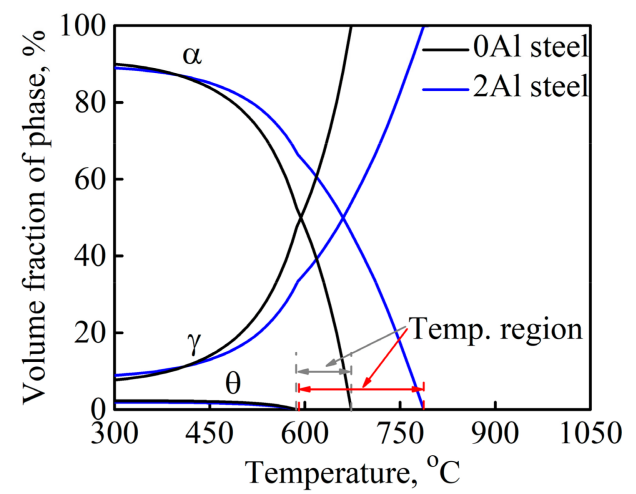

Figure 1. The equilibrium volume fraction obtained from Thermo-Calc of $0 \mathrm{Al}$ steel and $2 \mathrm{Al}$ steel. $\alpha$ : ferrite, $\gamma$ : austenite, $\theta$ : cementite, Temp. region: annealing temperature region for $0 \mathrm{Al}$ steel and $2 \mathrm{Al}$ steel.


Figure 2. The typical lath martensite microstructure after austenitization and quenching treatment of (a) $0 \mathrm{Al}$ steel and (b) $2 \mathrm{Al}$ steel and the corresponding prior austenite grain boundaries in the inserted images at the upper right corner. TEM micrographs showing lath austenite and ferrite of (c) $0 \mathrm{Al}$ steel annealed at $650{ }^{\circ} \mathrm{C}$ for $5 \mathrm{~min}$ and (d) $2 \mathrm{Al}$ steel annealed at $680{ }^{\circ} \mathrm{C}$ for $5 \mathrm{~min}$. (e) The volume fraction of austenite of $0 \mathrm{Al}$ steel and $2 \mathrm{Al}$ steel after being annealed at different temperatures for $5 \mathrm{~min}$. 
The engineering stress-strain curves of $0 \mathrm{Al}$ steel and $2 \mathrm{Al}$ steel after austenitization and intercritical annealing are shown in Figure $3 a, b$. The flow curves of both steels exhibit continuous yielding as expected. Furthermore, the ultimate tensile strength (UTS) of both steels increases with the elevated annealing temperature, while the yield strength (YS) decreases. The variation of the mechanical properties of both steels is comparable. Among the four groups of annealing processes for each steel, 0Al steel annealed at 650 and $660{ }^{\circ} \mathrm{C}$ and $2 \mathrm{Al}$ steel annealed at 680 and $690^{\circ} \mathrm{C}$ exhibit an excellent mechanical properties combination. However, more importantly, less discrepancy of mechanical properties is displayed within 2Al steel. The detailed YS, UTS and total elongation (TEL) of 0Al steel and 2Al steel are presented in Figure 3c. The variation of YS and UTS is only 22 and $61 \mathrm{MPa}$ within the $10{ }^{\circ} \mathrm{C}$ annealing temperature change for $2 \mathrm{Al}$ steel, while the variation is 50 and $98 \mathrm{MPa}$ for $0 \mathrm{Al}$ steel. From these data, it is indicated that more uniform mechanical properties can be obtained in the Al-added medium Mn steel during industrial production. Besides, it is worth noting that $2 \mathrm{Al}$ steel exhibits better plasticity than $0 \mathrm{Al}$ steel. The uniform elongation of $2 \mathrm{Al}$ steel annealed at $680{ }^{\circ} \mathrm{C}$ for $5 \mathrm{~min}\left(2 \mathrm{Al} 680\right.$ ) is $30.3 \%$, while that of $0 \mathrm{Al}$ steel annealed at $650{ }^{\circ} \mathrm{C}$ for $5 \mathrm{~min}(0 \mathrm{Al} 650)$ is only $24.5 \%$. As for the strain hardening rate of both specimens, as shown in Figure 3d, a large discrepancy is displayed during the initial stage of plastic deformation. The relatively high work hardening rate is shown in the 0A1650 specimen.
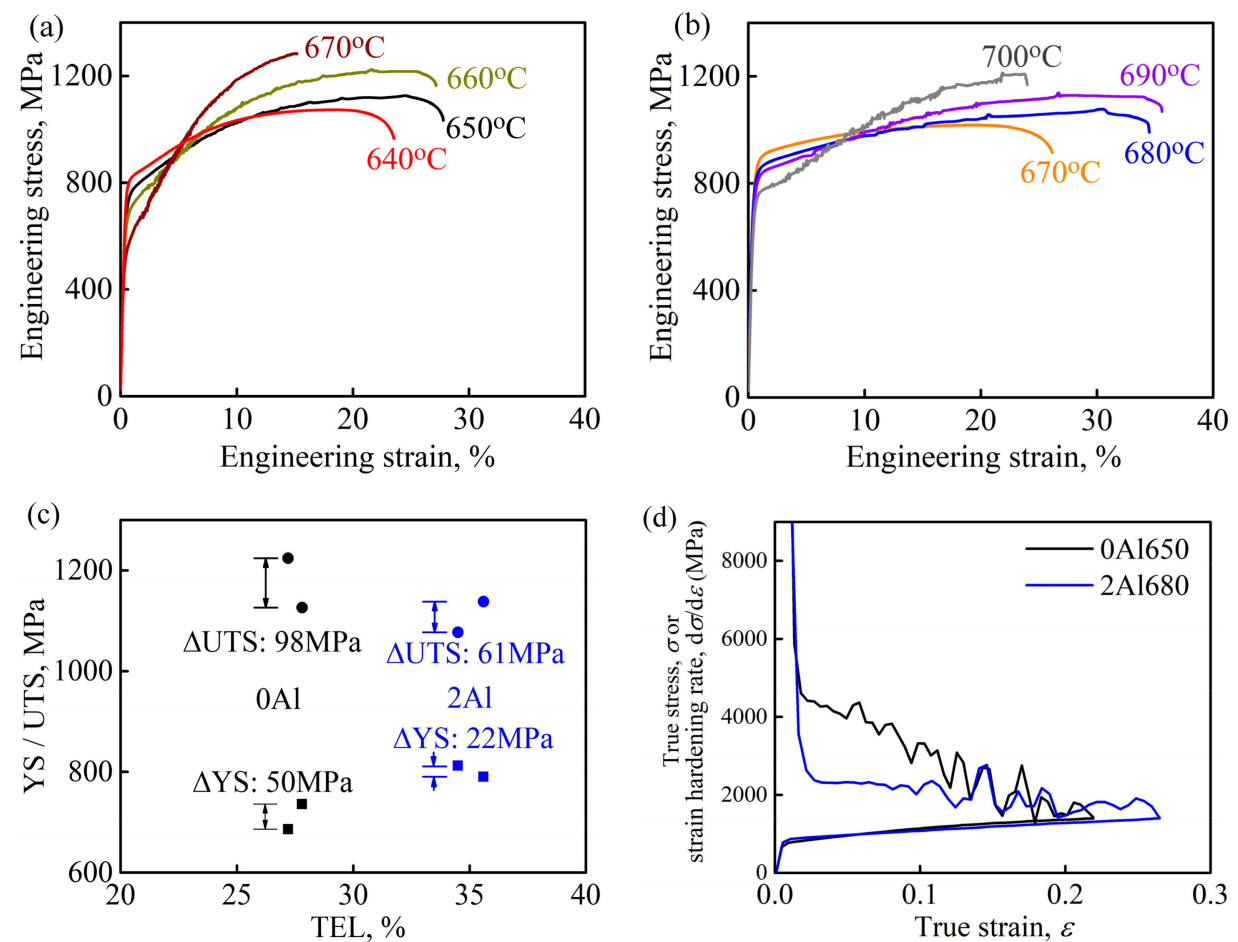

Figure 3. Engineering stress-strain curves of (a) $0 \mathrm{Al}$ steel and (b) $2 \mathrm{Al}$ steel annealed at different temperatures for $5 \mathrm{~min}$. (c) The mechanical properties of $0 \mathrm{Al}$ steel annealed at 650 and $660{ }^{\circ} \mathrm{C}$ and 2Al steel annealed at 680 and $690^{\circ} \mathrm{C}$, respectively. $\triangle \mathrm{YS}$ and $\triangle \mathrm{UTS}$ are the difference values of yield strength (YS) and ultimate tensile strength (UTS), respectively. (d) The strain hardening rate and true stress-strain curves of the 0Al650 and 2Al680 specimens.

The volume fraction and stability of austenite have a significant influence on the mechanical properties of TRIP steels $[11,19,33]$. The annealed microstructure of the 0Al650 and 2Al680 specimens was analyzed and characterized in detail. The initial volume fractions of austenite in the 0Al650 and 2 Al680 specimens are $42.7 \%$ and $45.6 \%$, respectively. The change in the volume fraction of austenite under different true strain during tensile deformation is shown in Figure 4a. As can be seen, less austenite is transformed into martensite during tensile deformation, and more austenite was finally 
retained in the 2Al680 specimen. This indicates that the austenite in the 2Al680 specimen exhibits higher mechanical stability than the austenite in 0Al650 steel. The mechanical stability of austenite can be described using the following equation [34,35]:

$$
V_{\gamma}=V_{\gamma 0} \exp (-k \varepsilon),
$$

where $V_{\gamma}$ is the volume fraction of austenite at a corresponding strain, $V_{\gamma 0}$ is the volume fraction of austenite in the unstrained state, $\varepsilon$ is the applied true strain and $k$ is the stability constant, and the numerical value is inversely proportional to the mechanical stability of austenite. The $k$ value for the 2Al680 specimen is 3.4, while that for the 0Al650 specimen is 5.9. This further shows a higher austenite mechanical stability in the 2Al680 specimen. Therefore, compared to the 0Al650 specimen, the TRIP effect of the 2Al680 specimen lasted to a higher strain and then a higher uniform elongation was achieved.


Figure 4. (a) Change in the volume fraction of austenite with the true strain of the 0Al650 and 2Al680 specimens. (b) The Mn and C concentrations in austenite ( $\mathrm{w} t \%)$ achieved by the EDS and $\mathrm{XRD}$, respectively.

In general, the mechanical stability of austenite depends on factors such as grain size, morphology and chemical composition [18,36,37]. As for the austenite in the 0Al650 specimen and the 2Al680 specimen, the size of the lath-shaped austenite can be represented by the equivalent circle diameter (ECD) using the following equation [38]:

$$
\mathrm{ECD}=(4 A / \pi),
$$

where $A$ is the area of the corresponding phase. The analysis was performed on the TEM images using the Image J software (Version 1.53e, National Institute of Health, Bethesda, MD, USA). In total, an average of 100 grains were analyzed and the grain size of austenite expressed by the ECD is $0.39 \pm 0.26$ and $0.41 \pm 0.22 \mu \mathrm{m}$ for 0Al650 specimen and 2Al680 specimen, respectively, indicating both steels have a similar austenite grain size. The chemical composition of austenite, especially $\mathrm{C}$ and $\mathrm{Mn}$, was measured and is shown in Figure $4 \mathrm{~b}$. The average $\mathrm{C}$ concentration in austenite of the 0Al650 specimen is $0.31 \pm 0.06 \mathrm{wt} \%$ and that for the $2 \mathrm{Al} 1680$ specimen is $0.27 \pm 0.04 \mathrm{wt} \%$. The Mn concentration in austenite of the 2Al680 specimen is approximately $13.2 \pm 1.5 \mathrm{wt} \%$, while the Mn concentration in austenite of the $0 \mathrm{Al} 650$ specimen is about $9.8 \pm 0.3 \mathrm{wt} \%$. Since the measured bulk composition of both steels is approximately $8 \mathrm{wt} \% \mathrm{Mn}$, this indicates $\mathrm{Mn}$ partitioning is more effective in the 2Al680 specimen than in the $0 \mathrm{Al} 650$ specimen. The main reason is that high partitioning efficiency is obtained at a higher intercritical annealing temperature due to the Al addition. Therefore, the higher mechanical stability of austenite in the 2Al680 specimen is exhibited and relatively low work hardening is achieved accordingly during the initial stage of plastic deformation of the 2Al680 specimen. 


\section{Conclusions}

In the present study, a two-step continuous annealing process was designed for cold-rolled medium Mn steels to avoid discontinuous yielding. The effect of $\mathrm{Al}$ on the microstructure and tensile properties during the above process was studied. The conclusions are as follows:

(1) The addition of $\mathrm{Al}$ can reduce the sensitivity of austenite volume fractions and tensile properties of medium Mn steels to the annealing temperature.

(2) The ductility of medium Mn steels can also be improved by Al addition due to the increased mechanical stability of the austenite which results from the effective partitioning of Mn into austenite during intercritical annealing at high temperature.

Author Contributions: Writing—original draft preparation and review, M.B.; writing—review and editing, D.Y.; project administration: G.W.; supervision, J.R. and K.L.; funding acquisition, supervision, project administration and writing - review and editing, H.Y. All authors have read and agreed to the published version of the manuscript.

Funding: This research was financially supported by POSCO and the National Natural Science Foundation of China (Grant Nos. 51722402), as well as by the 111 Project (Grant No. B16009) and the Liaoning Revitalization Talents Program (No. XLYC1907128).

Conflicts of Interest: The authors declare no conflict of interest.

\section{References}

1. Tonizzo, Q.; Mazière, M.; Perlade, A.; Gourgues-Lorenzon, A.F. Effect of austenite stability on the fracture micromechanisms and ductile-to-brittle transition in a medium-Mn, ultra-fine-grained steel for automotive applications. J. Mater. Sci. 2020, 55, 9245-9257. [CrossRef]

2. Yang, D.P.; Wu, D.; Yi, H.L. Comments on "The effects of the heating rate on the reverse transformation mechanism and the phase stability of reverted austenite in medium Mn steels" by J. Han and Y. K.; Lee, Acta Mater 67 (2014) 354-361. Scr. Mater. 2020, 174, 11-13. [CrossRef]

3. Mueller, J.J.; Matlock, D.K.; Speer, J.G.; De Moor, E. Accelerated ferrite-to-austenite transformation during intercritical annealing of medium-manganese steels due to cold-rolling. Metals 2019, 9, 926. [CrossRef]

4. Du, P.J.; Yang, D.P.; Bai, M.K.; Xiong, X.C.; Wu, D.; Wang, G.D.; Yi, H.L. Austenite stabilisation by two step partitioning of manganese and carbon in a Mn-TRIP steel. Mater. Sci. Technol. 2019, 35, 2084-2091. [CrossRef]

5. Luo, H.W.; Shi, J.; Wang, C.; Cao, W.Q.; Sun, X.J.; Dong, H. Experimental and numerical analysis on formation of stable austenite during the intercritical annealing of 5Mn steel. Acta Mater. 2011, 59, 4002-4014. [CrossRef]

6. Yang, D.P.; Wu, D.; Yi, H.L. Reverse transformation from martensite into austenite in a medium-Mn steel. Scr. Mater. 2019, 161, 1-5. [CrossRef]

7. Speer, J.; Rana, R.; Matlock, D.; Glover, A.; Thomas, G.; De Moor, E. Processing variants in medium-Mn steels. Metals 2019, 9, 771. [CrossRef]

8. Kaar, S.; Schneider, R.; Krizan, D.; Béal, C.; Sommitsch, C. Influence of the Quenching and Partitioning Process on the Transformation Kinetics and Hardness in a Lean Medium Manganese TRIP Steel. Metals 2019, 9, 353. [CrossRef]

9. Suh, D.W.; Kim, S.J. Medium Mn transformation-induced plasticity steels: Recent progress and challenges. Scr. Mater. 2017, 126, 63-67. [CrossRef]

10. Sun, B.; Fazeli, F.; Scott, C.; Brodusch, N.; Gauvin, R.; Yue, S. The influence of silicon additions on the deformation behavior of austenite-ferrite duplex medium manganese steels. Acta Mater. 2018, 148, 249-262. [CrossRef]

11. Gibbs, P.J.; De Moor, E.; Merwin, M.J.; Clausen, B.; Speer, J.G.; Matlock, D.K. Austenite stability effects on tensile behavior of manganese-enriched-austenite transformation-induced plasticity steel. Metall. Mater. Trans. A 2011, 42, 3691-3702. [CrossRef]

12. Lee, S.; De Cooman, B.C. On the selection of the optimal intercritical annealing temperature for medium Mn TRIP Steel. Metall. Mater. Trans. A 2013, 4411, 5018-5024. [CrossRef]

13. Furukawa, T.; Huang, H.; Matsumura, O. Effects of carbon content on mechanical properties of $5 \%$ Mn steels exhibiting transformation induced plasticity. Mater. Sci. Technol. 1994, 10, 964-969. [CrossRef] 
14. Fischer, F.D.; Reisner, G.; Werner, E.; Tanaka, K.; Cailletaud, G.; Antretter, T. A new view on transformation induced plasticity (TRIP). Int. J. Plast. 2000, 16, 723-748. [CrossRef]

15. Chiang, J.; Boyd, J.D.; Pilkey, A.K. Effect of microstructure on retained austenite stability and tensile behaviour in an aluminum-alloyed TRIP steel. Mater. Sci. Eng. A 2015, 638, 132-142. [CrossRef]

16. Blondé, R.; Jimenez-Melero, E.; Zhao, L.; Wright, J.P.; Brück, E.; van der Zwaag, S.; van Dijk, N.H. High-energy $\mathrm{X}$-ray diffraction study on the temperature-dependent mechanical stability of retained austenite in low-alloyed TRIP steels. Acta Mater. 2012, 60, 565-577. [CrossRef]

17. Hu, B.; Luo, H. A strong and ductile $7 \mathrm{Mn}$ steel manufactured by warm rolling and exhibiting both transformation and twinning induced plasticity. J. Alloys Compd. 2017, 725, 684-693. [CrossRef]

18. De Moor, E.; Matlock, D.K.; Speer, J.G.; Merwin, M.J. Austenite stabilization through manganese enrichment. Scr. Mater. 2011, 64, 185-188. [CrossRef]

19. Lee, S.; Lee, S.J.; De Cooman, B.C. Austenite stability of ultrafine-grained transformation-induced plasticity steel with Mn partitioning. Scr. Mater. 2011, 65, 225-228. [CrossRef]

20. Lee, S.J.; Lee, S.; De Cooman, B.C. Mn partitioning during the intercritical annealing of ultrafine-grained $6 \%$ Mn transformation-induced plasticity steel. Scr. Mater. 2011, 64, 649-652. [CrossRef]

21. Wang, X.G.; Wang, L.; Huang, M.X. Kinematic and thermal characteristics of Lüders and Portevin-Le Châtelier bands in a medium Mn transformation-induced plasticity steel. Acta Mater. 2017, 124, 17-29. [CrossRef]

22. Yi, H.L.; Sun, L.; Xiong, X.C. Challenges in the formability of the next generation of automotive steel sheets. Mater. Sci. Technol. 2018, 34, 1112-1117. [CrossRef]

23. Suh, D.W.; Park, S.J.; Lee, T.H.; Oh, C.S.; Kim, S.J. Influence of Al on the microstructural evolution and mechanical behavior of low-carbon, manganese transformation-induced-plasticity Steel. Metall. Mater. Trans. A 2009, 41,397-408. [CrossRef]

24. Sun, R.; Xu, W.H.; Wang, C.Y.; Shi, J.; Dong, H.; Cao, W.Q. Work hardening behavior of ultrafine grained duplex medium-Mn steels processed by ART-annealing. Steel Res. Int. 2012, 83, 316-321. [CrossRef]

25. Li, Y.; Huyan, F.; Ding, W. Microstructure and tensile properties of a 0.20C-4.86Mn steel after short intercritical-annealing times. Mater. Sci. Technol. 2019, 35, 220-230. [CrossRef]

26. Han, J.; Lee, S.J.; Lee, C.Y.; Lee, S.; Jo, S.Y.; Lee, Y.K. The size effect of initial martensite constituents on the microstructure and tensile properties of intercritically annealed Fe-9Mn-0.05C steel. Mater. Sci. Eng. A 2015, 633, 9-16. [CrossRef]

27. Xu, H.F.; Zhao, J.; Cao, W.Q.; Shi, J.; Wang, C.Y.; Li, J.; Dong, H. Tempering effects on the stability of retained austenite and mechanical properties in a medium manganese steel. ISIJ Int. 2012, 52, 868-873. [CrossRef]

28. Chandan, A.K.; Bansal, G.K.; Kundu, J.; Chakraborty, J.; Ghosh Chowdhury, S. Effect of prior austenite grain size on the evolution of microstructure and mechanical properties of an intercritically annealed medium manganese steel. Mater. Sci. Eng. A 2019, 768, 138458-138467. [CrossRef]

29. Bai, M.K.; Pang, J.C.; Wang, G.D.; Yi, H.L. Martensitic transformation cracking in high carbon steels for bearings. Mater. Sci. Technol. 2016, 32, 1179-1183. [CrossRef]

30. Hou, Z.R.; Opitz, T.; Xiong, X.C.; Zhao, X.M.; Yi, H.L. Bake-partitioning in a press-hardening steel. Scr. Mater. 2019, 162, 492-496. [CrossRef]

31. Jha, B.K.; Avtar, R.; Dwivedi, V.S. Structure-property correlation in low carbon low alloy high strength wire rods/wire containing retained austenite. Trans. Indian Inst. Met. 1996, 49, 133-142.

32. Dyson, D.J. Effect of alloying additions on the lattice parameter of austenite. Iron Steel Inst. 1970, $208,469-474$.

33. Ryu, J.H.; Kim, J.I.; Kim, H.S.; Oh, C.S.; Bhadeshia, H.K.D.H.; Suh, D.W. Austenite stability and heterogeneous deformation in fine-grained transformation-induced plasticity-assisted steel. Scr. Mater. 2013, 68, 933-936. [CrossRef]

34. Sugimoto, K.I.; Kobayashi, M.; Hashimoto, S.I. Ductility and strain-induced transformation in a high-strength transformation-induced plasticity-aided dual-phase steel. Metall. Trans. A 1992, 23, 3085-3091. [CrossRef]

35. Shi, J.; Sun, X.J.; Wang, M.Q.; Hui, W.J.; Dong, H.; Cao, W.Q. Enhanced work-hardening behavior and mechanical properties in ultrafine-grained steels with large-fractioned metastable austenite. Scr. Mater. 2010, 63, 815-818. [CrossRef]

36. Yi, H.L.; Lee, K.Y.; Bhadeshia, H.K.D.H. Mechanical stabilisation of retained austenite in $\delta$-TRIP steel. Mater. Sci. Eng. A 2011, 528, 5900-5903. [CrossRef] 
37. Zaefferer, S.; Ohlert, J.; Bleck, W. A study of microstructure, transformation mechanisms and correlation between microstructure and mechanical properties of a low alloyed TRIP steel. Acta Mater. 2004, 52, 2765-2778. [CrossRef]

38. Steineder, K.; Krizan, D.; Schneider, R.; Béal, C.; Sommitsch, C. On the microstructural characteristics influencing the yielding behavior of ultra-fine grained medium-Mn steels. Acta Mater. 2017, 13, 39-50. [CrossRef]

Publisher's Note: MDPI stays neutral with regard to jurisdictional claims in published maps and institutional affiliations.

(C) 2020 by the authors. Licensee MDPI, Basel, Switzerland. This article is an open access article distributed under the terms and conditions of the Creative Commons Attribution (CC BY) license (http://creativecommons.org/licenses/by/4.0/). 